\title{
Hacking in the University: Contesting the Valorisation of Ac- ademic Labour
}

\author{
Joss Winn \\ Centre for Educational Research and Development, University of Lincoln, Lincoln, UK, \\ jwinn@lincoln.ac.uk, http://staff.lincoln.ac.uk/jwinn
}

\begin{abstract}
In this article I argue for a different way of understanding the emergence of hacker culture. In doing so, I outline an account of 'the university' as an institution that provided the material and subsequent intellectual conditions that early hackers were drawn to and in which they worked. I argue that hacking was originally a form of academic labour that emerged out of the intensification and valorisation of scientific research within the institutional context of the university. The reproduction of hacking as a form of academic labour took place over many decades as academics and their institutions shifted from an ideal of unproductive, communal science to a more productive, entrepreneurial approach to the production of knowledge. A such, I view hacking as a peculiar, historically situated form of labour that arose out of the contradictions of the academy: vocation vs. profession; teaching vs. research; basic vs. applied research; research vs. development; private vs. public; war vs. peace; institutional autonomy vs. state dependence; scientific communalism vs. intellectual property.
\end{abstract}

Keywords: Hacking, Hackers, Academic Labour, Valorisation, History of Science, Marxism, Materialism

\section{Introduction}

In this article I argue for a different way of understanding the emergence of hacker culture. In doing so, I outline an account of 'the university' as an institution that provided the material and subsequent intellectual conditions that early hackers were drawn to and in which they worked.

It begins with a simple question: Why MIT and why 1959? There is general agreement among previous writers about when and where 'hacking' began but little attempt to explain how. Previous examinations have tended to explain hacking apart from the institutional context in which it developed, treating its origins in the academy as peripheral to more general categories of analysis such as an 'ethic' (Levy, 1984; Himanen 2001), 'activism' (Jordan 2008), 'counter-culture' (Turner 2006; Sterling 1992) or simply as part of a history of innovation (Raymond 1999). Even taken together, I believe such accounts present an incomplete history of hacker culture as it developed within the university during the 1960s and 1970s and largely ignore the conditions from which hacking emerged. By not fully accounting for the historical and material conditions out of which hacking emerged, they fail to offer an adequate approach to the study of hacking as an effective social and political movement, which is what compels many 'free software' and 'open source' hackers today (Kelty 2008; Soderberg 2008; Coleman 2012).

In this discussion of hacker culture, I argue that hacking was originally a form of academic labour that emerged out of the intensification and valorisation of scientific research within the institutional context of the university. Although first recognisable among a small group of academics and students in the early 1960s, the appearance of hacking should not be seen as suddenly occurring among a pioneering group of individuals but rather as an outcome of historical conditions that took place over many decades as academics and their institutions shifted from an ideal of "communism" or the "communal character of science" (Merton 1973, 273 ) to a more entrepreneurial approach to science (Etzkowitz 2001, 2002).

As Steven Shapin (2008) has shown, during the eighteenth century the State "increasingly gave systematic institutional form to the mobilisation of [scientific] expertise", and then in the nineteenth century science underwent a further transition from its characterisation as a per- 
sonal 'calling' to its transformation as labour or 'wage work' (Shapin 2008, 34). This dialectic between the 'disinterested', vocational and unproductive nature of academic work and its determinate form as productive paid work continues today, with some academics resisting the gradual influence of an 'entrepreneurial university' model, while others welcome it (Slaughter and Leslie 1997). As I will show, hackers and the first two decades of hacker culture are deeply embedded in this history and the institutional production of scientific knowledge.

My paper is roughly divided into two halves. The first half identifies early hackers as, broadly speaking, academics, working for and within 'the university', which I regard as a capitalist institution. Despite higher education being a well documented site of struggle between labour and capital, I try to show later in the paper that from its founding, MIT has been the model capitalist university. To begin with though, I provide a summary of my theoretical and methodological approach and show how it builds on examples of other scholarly work on hacking. In doing so, I also go beyond the main purpose of this paper by arguing for the dialectical, historical materialist study of hacking in general, and not just its emergence. The second part of this paper sketches, very briefly, the historical development of MIT up to and including the emergence of hacking in the early 1960s through to the early 1980s. What guides this narrative, which I outline in four parts, is the imperative of valorising academic labour in the service of capital. I draw on secondary sources and have tried to distil this research into a discussion of events that highlights the validity of my argument and offers both an interesting and compelling answer to my initial question: why MIT, why 1959?

What I outline in this paper should more properly be developed into a book, which would allow more space to include further research into the institutional history of science and firsthand interviews with some of the people involved. It would also allow more space to reflect on the growing range of research into hacking, especially from the Marxian perspective. What I hope to show within the limits of this paper is that a study of higher education institutions and their essential role in twentieth century capitalism has much to offer scholars of hacking, open source software and its derivative social movements. So far, writers have hinted at the significance of the academy in hacker culture, but barely touched the surface in uncovering the historical, material and social conditions from which hacking emerged and the effect this has had on the resulting free software, open source and free culture movements.

\section{In, Against and Beyond a Liberal Critique within Liberalism}

"[...] as the proletariat still acts, during the period of struggle for the overthrow of the old society, on the basis of that old society, and hence also still moves within political forms which more or less belong to it, it has not yet, during this period of struggle, attained its final constitution, and employs means for its liberation which after this liberation fall aside" (Marx 1874).

My interest here is in the early period of hacking, framed crudely by the arrival of the PDP1 computer in 1961 and the departure of Richard Stallman from MIT in 1984. Therefore, I am interested in the emergence of a particular subjectivity ('hackers') and effort ('hacking') that was mostly confined to a small number of American universities, in particular MIT. During this period and especially during the 1960s and early 1970s, hackers were, by and large academics: teachers, researchers, research assistants and students, and as such hackers were a form of academic labour which emerged from and was subject to specific historical and material conditions. In taking this approach, I do not view hackers as mere instruments of the institutional context they were working in but as a class (i.e. the 'working class') that must sell its labour to the owners of the means of production (i.e. the 'capitalists'). This historically unique form of social relations can be summarised as the 'capital relation', in which labour acts in accordance with its interests as a class that is forced to reproduce itself as labour and thus reproduce the capital relation. This constant, naturalised confrontation with capital (i.e. 'work') gives rise to a series of contradictions in which labour finds itself a socially productive force producing outcomes that are increasingly appropriated for private gain. Attempts to resist, subvert, overcome and 'hack' the capital relation are a result of this contradiction and more generally referred to as 'working class struggle'. In this way, my approach is clearly in 
contrast to a reified understanding of hackers as individual "heroes" (Levy 1984), "wizards" (Hafner and Lyon 2003) and "real programmers" (Raymond 1999).

In taking this view, I also want to acknowledge earlier important studies of hackers and recognise that the motivations of individuals are complex, their subjectivities cannot easily be explained and an understanding of the day-to-day conditions of our lives can be approached in many ways. For example, Stephen Levy's (1984) Hackers: Heroes of the Computer Revolution employs a biographical approach. It is the classic text on hackers and the only attempt to develop a coherent history. However, its weakness is that it is a journalistic account of those 'heroes', making only cursory mention of the institutional, economic and political conditions they were working in. Levy was writing for a popular audience during Reagan's neoliberal government which re-asserted traditional liberal ideals of individualism and individual responsibility. A fuller critique of Levy's account should recognise that the achievements of those 'heroes' might be better understood through a critique of neo-liberal social theory. Nevertheless, it is a fascinating account of the subjective motivations of the individuals involved and a pivotal book in the elaboration of hacker culture.

Similarly, Tim Jordan's (2008) Hacking: Digital Media and Technological Determinism, draws largely on literature written by hackers themselves and also presents them as heroic "warriors" and "hacktivists". Where Jordan differs to Levy is that he presents a positive account of hacking as a social and political project. What makes Jordan's book particularly valuable is his argument that "hacking both demands and refutes technological determinism" (Jordan 2008, 133). That is, hackers both reinforce the general sense of technological determinism in society and yet work towards its critique.

Christopher M. Kelty (2008) goes further to show how the values of free software hackers have extended to the broader 'free culture' movements such as Open Access and Creative Commons. He argues that the activity of geeks (among whom he includes hackers) can be conceived as a 'recursive public', "a public that is constituted by a shared concern for maintaining the means of association through which they come together as a public" (Kelty 2008, 28). Kelty's work is an important scholarly contribution to the study of hacker culture, with a particular focus on its cultural and political role in the development of the Internet since the mid-1990s. The identification of a 'recursive public' (recognised by other writers but not so eloquently defined) is especially perceptive and provides a useful analytical tool with which to understand current hacker culture and its antecedents inside and outside the academy. The limitation of his approach is that Kelty's 'recursive public' of geeks is reified, existing 'independent of, and as a check on, constituted forms of power, which includes markets and corporations" (ibid). Kelty's 'recursive public' presents a positive conception of a reformist social movement, rather than conceiving 'recursion' as a historical social process through which political struggle is being generalised through the use of the Internet.

Along similar lines, E. Gabriella Coleman (2012) identifies hackers and hacking as a "liberal critique within liberalism". Just as Jordan and Kelty situate hackers within a contested world of their own making, Coleman identifies hackers as in and against a dominant political discourse. This suggests that the work of hackers can be understood as both struggle and critique. From this position, hacker culture might be seen as one of the most influential social movements in recent history, yet one which continues to struggle within a liberal, capitalist world-view, continually confronted by the organising principle of private property and wage work. By situating hacker culture as a liberal critique within liberalism, Coleman identifies the limits and the opportunities it presents within liberal capitalist society.

Johan Soderberg (2008) recognises hacking most clearly as a political project but only briefly mentions the formative period that concerns this paper. He rightly mentions the development of the telephone infrastructure, Norbert Wiener's theory of Cybernetics and its application in war-time funded research projects, which would eventually go on to develop the Internet. He also identifies the anti-war and appropriate technologies movements as examples of how personal computing grew out of 1960s counter-culture (Turner (2006) and Markoff (2005) provide fuller accounts of this). However, much of Soderberg's book is an examination of hacking using the categories of Marx's critique of political economy (capital, class, value, labour, commodities, etc.). In doing so, it is the only book-length study of hacking 
which attempts to methodologically examine hacking from the point of view of a critique of liberalism, rather than starting from a naturalised, liberal understanding of categories such as property, work, production and exchange. For this reason, it is an important book.

Jordan, Kelty, Coleman and Soderberg each go some way to show that a study of hacker culture can reveal to us an immanent critique of liberal capitalism: it is a culture that is both in and against; it is complicit but points to a way beyond capitalism through the development of intellectual and practical tools such as copyleft and the sharing and co-production of free software. Soderberg is most clear about this yet although he discusses hacking using the critical categories developed by Marx, he does not fully develop a negative critique of hacker culture. In the end, Soderberg's rich account of hacking as an emergent form of "play struggle" is an account of hacking as an emancipatory form of work. His account offers a Marxist critique from the standpoint of labour/hackers as the revolutionary subject in capitalism, rather than elaborating on Marx's own analysis of capital as the "automatic subject" (Marx 1976, 255) - a determinate logic of "self-valorising value". (Postone 1993, 75-77).

If, following Soderberg, we view early hackers as a form of labour it allows us to situate the role of hacking in the production of value and its relationship to capital. For Marx and later critical social theorists (e.g. Neary 1999; Clarke 1980; Postone 1993), labour within capitalism cannot be emancipatory as long as it remains the source of capitalist value. Marx's labour theory of value analyses labour in both its concrete and abstract forms. In its concrete physiological form, labour is the expenditure of human 'labour power', which when employed as labour produces 'use values' - products and services that have a utility. A hacker programming a PDP-10 computer is useful labour. When engaged productively, that is, when producing a use value for the purpose of exchange (e.g. computer programming in exchange for a government grant expressed in the form of a wage), the use value becomes a "commodity' and the labour of an individual becomes a social form of labour that is measured by time (e.g. the duration of the government grant or employment contract).

Measured socially, an individual's labour is equated with all other forms of labour involved in the diversity of capitalist production. Marx referred to this form of labour as 'abstract labour', where the specific quality of labour is not simply its concrete physiological character but also its quantitative equivalence as value. With this analysis, Marx attempted to show how the substance of value is in fact abstract labour, measured socially by the amount of time required on average to produce a given use value for the purpose of exchange. When subject to this analysis, all types of labour in all their diversity are equated qualitatively, as labour power, and quantitatively, as value, the substance of which is abstract labour measured by socially necessary labour time. Thus labour becomes "a jelly of abstract human labour" (Marx 1978) employed in the capitalist production of value. Concrete mental and physical labour is but the form of appearance of abstract human labour and the work of hackers is but one form of this appearance.

Taking this approach, the work of hackers, as it emerged out of the research laboratories of a few American universities in the late 1950s, assumes a different character. We can view it both in its concrete appearance as mischievous, playful, meritocratic and at times, explicitly political, but mindful that as waged employment in a university, its primary purpose was to produce value. The development of this approach to the study of hackers and hacking should in fact result in a much stronger defence of the 'recursive public' of hacker culture as it is increasingly incorporated into neo-liberal policy and methods of valorisation as we have recently seen in policy statements on open science and open data (Foreign and Commonwealth Office 2013; Cabinet Office 2013).

Thus, building on Coleman and Soderberg's work, I also view hacking as an expression of political struggle; one that "still moves within [liberal-capitalist] political forms which more or less belong to it" (Marx 1874). However, these authors do not provide a critique of hacking from the standpoint of capital as the "automatic subject" which reproduces hacker culture. Once we take such an approach, the labour of hacking as a constituent part of capital and primary source of value can be understood as struggling against the conditions of its own making and therefore must itself be abolished rather than reified. At that point, "the means for 
its liberation [...] fall aside" (Marx 1874) and the labour of hacking is wholly reconstituted as a different form of social wealth, beyond and no longer against the social relations of capital.

Whereas a liberal critique within liberalism finds 'difference' among the social relations of people (e.g. free vs. open source hackers; hackers vs. hacktivists), a negative, dialectical critique of liberalism uncovers the contradictions of capitalist social relations, here expressed by hacking as a form of labour that is increasingly anachronistic in contemporary society.

Such a critique is immanent because it locates those contradictions historically and temporally, rather than as 'natural', trans-historical conditions. In this way, hacking is located as a peculiar, historically situated form of labour that arose out of the contradictions of the academy: vocation vs. profession; teaching vs. research; basic vs. applied research; research vs. development; private vs. public; war vs. peace; institutional autonomy vs. state dependence; scientific communalism vs. intellectual property. This dialectical method of examination is based on the precondition of the contradiction of labour at the heart of capitalism and to which aspects of hacker culture can be understood as a negative response.

The contradiction of labour is that the development of science and technology increasingly renders obsolete earlier forms of organising production and therefore the human labour time required in the production of social wealth. Yet despite being increasingly anachronistic in the development of capitalism, it was Marx's contention that the direct expenditure of combined human intellectual and manual labour remains necessary to the development of capital as its only source of value. In short, capital remains dependent on the generalised mass of commodified labour (i.e. wage work) of the working class, which includes hackers, as a source of profit ('surplus value'), yet through the innovative use of science and technology capital increasingly renders that labour superfluous i.e. a general crisis of under-employment, or stated another way, a 'surplus population' (Postone 1993, 34). A dialectical approach to understanding the implications of this fundamental contradiction of capital is thus a negative critique in that it identifies what is and therefore what is not but could be. (Postone 1993, 89)

It follows that we can attempt to interpret aspects of hacking itself as an immanent critique, which is in and against the existing social conditions of liberal capitalist society and an attempt to move beyond the contradictions of capitalist society, which the labour of hackers reveals to us. Thus, by situating hacking in its liberal context and positing hacker culture as a negative response to the developing contradictions of modernity, hacking can be understood as a utopian form of labour that in seeking to overcome the organising principle of property and wage work, will abolish the compulsive necessity of itself.

\section{The Valorisation of the Academy}

Having argued that the earliest hackers were a form of academic labour, I now want to discuss the methods by which this labour was valorised and reproduced. To begin to unfold a history of hacking, in which Richard Stallman notably left the academy when confronted by the commercial enclosure of his work, we must understand at least four cumulative methods of valorisation within US higher education leading up to the early 1980s:

- the provision of 'land grants';

- the use of patents;

- the massive injection of war-time funding;

- and the development of venture capital.

Each of these methods points to the combined role of the State and of industry in the development of the university and therefore in the formation of hacker culture and any 'ethic' we may synthesise from that culture. By laying out this formative history, we can locate Stallman and other hackers within an institutional context that had been developing for many decades, and the development of techniques such as the General Public License (GPL) as a negative response against the conditions of their own formation.

Prior to outlining the specific methods of valorisation that have taken place within the US academy, I should briefly explain what I mean by this term. 
In his critique of political economy, Marx developed the "general formula of capital", M-C$M^{\prime}$. This refers to the way money $(M)$ is advanced to purchase a commodity $(C)$ in order to produce new commodities that are sold for a profit, creating more money. With the commodities purchased, 'the capitalist' buys the means of production (MP) and labour-power (L), transforming money capital into productive capital $(P)$. As a generalised method of creating wealth, this process is historically unique to capitalism. The circuit of capitalist valorisation can be illustrated as:

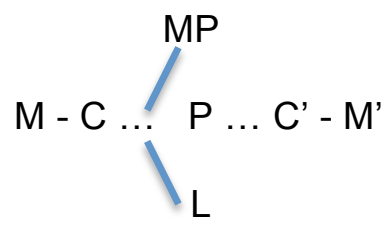

In capitalist societies, the university is a means of production. In this context, the 'means of production' refers to the university's structural, technological and bureaucratic configuration for the production of knowledge. The university incorporates prior knowledge into its production process and the knowledge it produces is exchanged through teaching, consultancy, government grants, technology transfers, etc. and so offered as the object of labour elsewhere, resulting in capital accumulation (i.e. 'economic growth'). 'Labour-power' refers to creative human potential, which is applied as 'labour'. The individual exchanges their human 'labour-power' (itself a commodity) for a wage, and the required application of 'labour power' as 'labour' is defined by their employment contract. It is an individual's potential to undertake labour (i.e. 'labour-power') and the specific application of that potential within the given academic context that she works that we refer to ordinarily as 'labour'. Combining labour-power with the means of production produces a 'use-value' (e.g. a product or service) for the purpose of exchange upon which it will realise an 'exchange value', or more commonly 'value', in the form of money. The duality of having a use-value and an exchange-value is what defines a 'commodity'. Labour is itself such a commodity, and labour produces such commodities. In this way, labour is the original source of value and abstract labour, as discussed above, is the 'substance' of value.

In the context of the university, we might well ask, "who is the capitalist" in this valorisation process? On one level, as I will show, we can point to a combination of state and industry actors, as well as notable university leaders each of whom takes on the role of 'capitalist' by helping to ensure the advance of money capital and the production of commodities. However, on a more abstract, social level, as Marx described, 'capital' itself is the "automatic subject" (Marx 1976, 255-256), a determinate logic of valorisation, which 'the capitalist' personifies.

"It is only insofar as the appropriation of ever more wealth in the abstract is the sole motive behind his operations that he functions as a capitalist, i.e., as capital personified and endowed with consciousness and a will. Use-values must therefore never be treated as the immediate aim of the capitalist; nor must the profit on any single transaction. His aim is rather the unceasing movement of profit-making" (Marx 1976, 254).

In a mature, industrial capitalist economy, both the owners of capital (e.g. the state, trustees, governors) and wage-workers (e.g. teachers, cleaners, hackers) are subsumed under this totalising social imperative. Increases in productivity across society compel the owners of capital to act within the 'logic' of self-valorising value (i.e. capital) as they compete with other local, national and international capitals to produce value relative to the productivity of labour-power and the means of production combined. An initial increase in productivity will allow a greater amount of surplus value (i.e. profit) to be produced until those improvements in productivity have been generalised across society, and competing capitals undercut each other so as to win market share. This "iron law of competition" (Heinrich 2012, 108) compels the owners of capital (who are capital personified), to organise production around this imperative. By undertaking research and teaching students, universities are both subject to this 
production process and are vital to the improvement of productivity and labour elsewhere in society.

It is within this context of US capitalist industrialisation in the late $19^{\text {th }}$ century that 'land grant' universities were established, setting in motion the widespread valorisation of natural capital through the sale of federal land so as to establish the structural, technological and bureaucratic configuration for the production of knowledge. "Nowhere was the trend towards occupational utility more apparent or more widely illustrated than in the development of landgrant colleges" (Lucas 1994, 146).

\subsection{Industrial Workshops}

"[...] the endowment, support, and maintenance of at least one college where the leading object shall be, without excluding other scientific and classical studies and including military tactics, to teach such branches of learning as are related to agriculture and the mechanic arts... in order to promote the liberal and practical education of the industrial classes in the several pursuits and professions in life" (Morrill Act 1862).

The history of hacking in the early 1960s involves a few US research universities with MIT at the centre. For this reason, I focus here on institutional changes within MIT. To begin to answer the question, "why MIT? Why 1959?", we unfold an early history of hacking as academic labour that is tightly bound to the institution of the university and the social, political and economic conditions in which higher education developed in the United States during the $20^{\text {th }}$ century.

MIT was one of the first 'land grant' universities - institutions oriented towards science and technology and federally funded to "promote the liberal and practical education of the industrial classes". Land grants were provided under the Morrill Act of 1862, being a response to many years of campaigning by farmers and agriculturalists for research institutions that would contribute to the improvement of US farming. The Act led to States being allocated 30,000 acres of federal land that was to be sold in order to establish endowment funds for such universities. The European Polytechnic movement was also gaining popularity in the US and seen as a model for new applied science universities in contrast to the largely teaching universities that existed at that time. Over 100 'land grant universities' were established across the USA, instituting a system of higher education that served the agricultural and industrial economy and increased access to education for the new class of industrial workers. Land grant universities can be seen as both a way to train labour and in so doing raise the productivity of American industry and agriculture at that time, as well as a response to calls for the democratisation of higher education.

Until the Land Grant universities of the late 19th century, there were no 'research universities' in the US and even academic staff dedicated to research were rare (Atkinson and Blanpied 2007). As a land grant university, MIT has always had close contact with industry; early in its formation MIT employed professional engineers as members of its academic faculty. By the 1920s, these academics were acting as consultants to industry to the extent that there was tension among MIT staff, between those who felt it was their job to focus on teaching and the needs of students, and those who spent a significant portion of their time focusing on the needs of industry. During the Great Depression of the 1930s, MIT was accused by private consultants of subsidising academics to consult, which amounted to unfair competition. As a result of these tensions, a policy was established called the 'one fifth rule', whereby MIT academics could spend a day a week using MIT resources to undertake consulting services. The role of academics acting as consultants is now commonplace in universities but in the US it was at MIT, a land grant university, where the practice was first formalised (Etzkowitz 2002).

In American Higher Education. A History, Lucas identifies the "imperatives for change" during the mid-nineteenth century as a "potent combination of social, political, cultural, and economic factors". He points to demand for new technical knowledge, urbanisation, an increasingly secular society and "most important of all perhaps was the growth in surplus capi- 
tal potentially available for institution-building from the accumulated fortunes of industrial entrepreneurs, railroad tycoons and business magnates" $(1994,142)$. The Morrill Act was a response to this demand, which transformed US higher education. It marked a new period in the democratisation of education as well as re-defining the purpose of higher education to include research as well as teaching. It also established a new relationship between the state and academics with the expectation that academic labour would be put to productive use in training (i.e. improving) industrial and agricultural labour. The subsequent Hatch Act (1887) and Smith Lever Act (1914) led to the establishment of agricultural research stations affiliated with land-grant universities and, for the first time, the widespread co-operation between the State, the academy and industry, for the production of knowledge and the reproduction of labour.

In 1890, F. H. Stoddard, a New York University professor, wrote that the university "has ceased to be a cloister and has become a workshop" (quoted in Lucas 1004, 144). At MIT, 70 years later, that "workshop" for the production of knowledge had grown into a complex genealogy of research labs and projects from which hacker culture emerged as a particular, concrete form of academic labour.

\subsection{A Laboratory of Patent Economics}

The federal government set in motion the valorisation of capital and subsequent labour required to undertake industrial and agricultural research and consultancy. These land grant universities, such as MIT, then looked for ways to sustain and grow their institutions and the formalisation of consultancy to industry was one method. In addition to consultancy, in 1932 MIT created one of the first university patent policies. Faced with financial uncertainty, this represented a desire by the institution to produce further value from scientific research as was already taking place in industry. It also represented a systematic move towards defining the outcomes of university research as a legal form of property - 'intellectual property'.

Patenting has been the subject of much heated debate throughout the history of the modern university (e.g. see Mowery et al. 2004, ch. 3; Johns 2009, ch. 14). Debates often focused around the ethics and benefits of patenting inventions derived from research, with some academics believing that patents were necessary to protect the reputation of the institutions, for fear that the invention might be "wrongfully appropriated" by a "patent pirate" (Mowery 2004, 36). This view saw patents as a way to enhance the public good and advance social welfare by protecting the invention from "pirates" who might otherwise patent the invention themselves and charge extortionate prices. Within the early pre-WWII debates around the use of patents by US universities, it was this moral argument of protecting a public good that led to patents being licensed widely and for low or no royalties. The few universities that began to apply for patents on their inventions at this time did so through the Research Corporation, rather than directly themselves, so as to publicly demonstrate the disinterested, communitarian nature of their research.

The Research Corporation was established in 1912 by Frederick Cottrell, a scientist at the University of California, Berkeley, as "a sort of laboratory of patent economics" (Mowery 2004, 60). Cottrell had received six patents for his work on the electrostatic precipitator and felt strongly that his research would receive more widespread utility if it were patented than if it were provided to the public for free. Cottrell did not wish to involve university administrators in the management of the patents, as he believed this would set a dangerous precedent of too closely involving non-academics in the scientific endeavours of researchers. He also worried that it would place an expectation on academics to continue to produce work of commercial value, increasing the "possibility of growing commercialism and competition between institutions and an accompanying tendency for secrecy in scientific work" (Cottrell quoted in Mowery et al. 2004, 60).

For the first couple of decades of the Corporation, much of the income came from Cottrell's patents. As these revenues decreased, the Research Corporation looked for other sources of income. This coincided with the Great Depression and a time when universities were struggling to remain solvent. As part of a strategy to sustain MIT its President, Karl 
Compton, charged Vannevar Bush, then Dean of MIT's School of Engineering, with developing a patent policy for the university. With this, MIT asserted an institutional claim on any invention resulting from research funded by the university. However, the patent committee recommended that MIT should be relieved "of all responsibility in connection with the exploitation of inventions while providing for a reasonable proportionate return to the Institute in all cases in which profit shall ensue" (quoted in ibid 64). To undertake this, MIT drew up an "Invention Administration Agreement' (IAA) with the Research Corporation, which, significantly, created a precedent for other universities to follow and also marked a clear shift from the individual ownership of research inventions, many of which were donated to the Corporation by philanthropic academics, to institutional ownership, which anticipated an income from that research (a 60/40 split between MIT and the Corporation). As a result, Cottrell's original vision of creating an independent charitable organisation that turned patent income into grants for further scientific work, had to meet the challenges of the Depression and the unpredictable nature of successfully exploiting research.

MIT institutionalised this method of valorisation through their relationship with the Research Corporation, using it to exclusively manage its patents from 1937 to 1946 . The Institute eventually cancelled its contract with the Corporation in 1963, by which time concerns about directly managing the commercial exploitation of its research had largely disappeared and the in-house skills to undertake the necessary administration had been developed over the course of their relationship with the Research Corporation. The partnership between MIT and the Research Corporation was never very profitable, with the Corporation making net losses during the decade that it exclusively managed MIT's patents. However, during and following WWII, the scale of research activity in US universities markedly increased. Mowery et al. notes that "the expansion of military and biomedical research conducted in US universities during and after the war had increased the pool of potentially patentable academic inventions, and federal funding agencies compelled universities to develop formal patent policies during the early post-war period. The Research Corporation negotiated IAAs, modelled on the MIT agreement, with several hundred other US universities during the 1940s and 1950s" (ibid 66).

The latter years of the Research Corporation were spent trying to build relationships with university staff in an effort to develop the necessary skills to identify potentially commercial inventions across different research disciplines. Ironically, in its attempt to off-load some of the administrative costs to institutions the Corporation effectively trained university administrators to manage without its assistance, eroding the competitive advantage that the Corporation previously held. During the 1970s, universities were also 'cherry picking' inventions to patent themselves, rather than the Research Corporation, in an effort to benefit from all of the potential revenue rather than a cut of it. This can be seen as a clear indication that earlier concerns about universities directly exploiting their research had been largely overcome, and that during the 1960s and 1970s, the institutional structures and skills within the larger research universities like MIT, had been put in place, partly with the assistance of the Research Corporation. MIT was at the avant-garde of valorising academic labour and provided a model for other universities to follow.

An understanding of the role of patents in the valorisation process shows how the academy struggled both ethically and procedurally to fully assimilate a process by which research outcomes are converted into a direct source of value. It took almost 50 years, from the creation of MIT's patent policy to the generalisation of university patenting with the Bayh-Dole Act in 1980 , for this conversion to be fully absorbed into the institutional form of the American university.

\subsection{The Military-Industrial-Academic Complex}

Federal funding to US universities was not a significant source of research income until the Second World War. Scholars such as Lowen (1997) and Etzkowitz (2002) point to the experience of the First World War and then the Great Depression as stimuli for the closer relationship between universities and federal government. During the turbulent first two decades 
of the $20^{\text {th }}$ century, MIT's leaders made a conscious effort to develop relations with industry (Kaiser 2010). In 1919, MIT President Richard Maclaurin implemented a 'Technology Plan' based upon consultancy to industry in an effort to raise the $\$ 8 \mathrm{~m}$ deemed necessary to keep the Institute solvent. Although MIT failed to reach its target, the legacy of the plan was very significant in that the Institute had established its Division of Industrial Cooperation and Research (DICR), an office that negotiated research contracts with industry. Being unique among universities at that time in having an office that could handle a large number of external contracts, MIT was in an advantageous position when the US entered WWII having bureaucratic processes in place to handle the large increase in government research contracts (Canizares 2007). The DICR was subsequently used as a model for how government transferred funds to other universities during World War II (Kaiser 2010; Green 2010; Etzkowitz 2002; Lowen 1997).

By the time World War II began, leading academics such as Vannevar Bush, who was then Head of the Carnegie Institute of Washington, had successfully lobbied government to create a federal agency to co-ordinate military research. In contrast to the relatively low position accorded to academic scientists during the First World War, Bush and others sought to place academics at the heart of government policy-making through the establishment of the National Defense Research Committee (NDRC) (1940-1). In his memoirs, Bush is clear about his motivations for establishing the NDRC: "There were those who protested that the action of setting up NDRC was an end run, a grab by which a small company of scientists and engineers, acting outside established channels, got hold of the authority and money for the program of developing new weapons. That, in fact, is exactly what it was" (Bush 1970, quoted in Pielke 2012).

The composition of this ground-breaking committee is revealing: of the eight original members, four were academics, two were from the military, one from business and another the US Commissioner for Patents, underlining the strategic relationship between government, industry and the academy. The most significant achievement of the NDRC's short history was the formation of the MIT Radiation Lab ('Rad Lab'), which developed radar technology during the war. The Rad Lab (1940-45) was shut down at the end of the war, but became the model for future 'labs' at MIT and elsewhere, such that there is a significant 'genealogy' of labs (e.g. the Al Lab), projects (e.g. 'Project MAC') and people (like Richard Stallman) that can be traced back to the Rad Lab and the NDRC.

In 1941, the NDRC was superseded by the Office of Scientific Research and Development (OSRD) (1941-7), led by Vannevar Bush. The OSRD was a fully-fledged funding agency for distributing public money to support research which it co-ordinated. Five universities became the main beneficiaries of this funding during the War: MIT, John Hopkins, Berkeley, Chicago and Columbia, resulting in a mass migration of scientists from universities across the country to work at one of these select centres of research.

The increase in research funding to US universities during the period of WWII was huge. Mowery et al (2004) show that federal R\&D funding increased fifteen-fold. MIT was the largest single recipient, receiving almost seven times more than Western Electric who were the largest commercial recipient. Consequently, the contractual arrangements developed at MIT prior to and during WWII, and the level of funding administered on behalf of the federal government, fundamentally changed the relationship between the State and universities. The Second World War solved MIT's inter-war financial crisis as Forman (1987, 156-157) has noted: "MIT, on the inside track, emerged from the war with a staff twice as large as it had had before the war, a budget (in current dollars) four times as large, and a research budget ten times as large $-85 \%$ from the military services and their nuclear weaponeer, the AEC [Atomic Energy Commission]".

An examination of the funding arrangements for academic R\&D during the post-WWI period reveals dramatic change, not only in the amount of public money being transferred to universities, but also in the way that academic scientists developed much closer relationships with government and re-conceptualised the idea, practice and purpose of science. A new ideology of science was formed, encapsulated by its chief architect, Vannevar Bush in the pivotal report Science: The Endless Frontier (1945). This famous report to President Roose- 
velt redefined the 'social contract' between scientists and government. Crucially, the report argued for the importance of funding "basic research" as the catalysis for economic growth: "Basic research leads to new knowledge. It provides scientific capital. It creates the fund from which the practical applications of knowledge must be drawn. New products and new processes do not appear full-grown. They are founded on new principles and new conceptions, which in turn are painstakingly developed by research in the purest realms of science" (Bush 1945).

In the report, Bush argues that "basic scientific research is scientific capital" necessary in order to create "vigorous enterprises" and that Europe can no longer be depended upon "as a major source of this scientific capital". He then asks the rhetorical question: "How do we increase this scientific capital?" The answer being through academic research: "we must strengthen the centers of basic research which are principally the colleges, universities, and research institutes. These institutions provide the environment which is most conducive to the creation of new scientific knowledge and least under pressure for immediate, tangible results. With some notable exceptions, most research in industry and Government involves application of existing scientific knowledge to practical problems. It is only the colleges, universities, and a few research institutes that devote most of their research efforts to expanding the frontiers of knowledge" (Bush 1945).

Bush's success in redefining the role of universities in the valorisation of capital led to dramatic changes in their institutional forms and the movement of academic labour from institution to institution and from research project to research project. So-called 'labs', like MIT's Lincoln Lab were in fact large semi-autonomous organisations employing thousands of researchers and assistants. They became the model for later 'science parks' and spawned projects and research groups which then became independent 'labs' with staff of their own, such as the Al Lab. The University of Stanford learned from this model and it arguably led to the creation of Silicone Valley (Etzkowitz 2002; Gillmor 2004).

The Al Lab where Richard Stallman worked from 1971-1984, is legendary in the history of hacking (Levy 1984). Like many MIT labs, its origins can be traced back to the Rad Lab through the Lincoln Lab and Research Laboratory of Electronics (RLE), where some of its personnel formerly worked and developed their thinking around Artificial Intelligence. The Al Lab began as a research group within Project MAC (Multiple Access Computer and MachineAided Cognition). Project MAC was set up in 1963 and originally led by Robert Fano, who had worked in the Rad Lab. J.C.R. Licklider, who helped establish the Lincoln Lab and worked at RLE, succeeded Fano as Director of Project MAC in 1968, having worked for DARPA, an agency of the Dept. of Defence, since 1962 and was responsible for the original Project MAC grant. Licklider remained Director of Project MAC until 1971, a year after Marvin Minsky, who worked in Project MAC's Al research group, led the split to form the Al Lab in 1970, shortly before Stallman arrived as a research assistant. Little more needs to be said here about the Al Lab as it is well documented by Levy (1984) and Williams and Stallman (2010) but what should be underlined is the extent to which the Al Lab, referred to by Stallman as the "Garden of Eden", was the strategic outcome of institutional, government and commercial relationships stretching back to the NDRC, the Rad Lab and that "grab" for the development of weapons by "a small company of scientists and engineers".

As post-war economic conditions and government funding priorities shifted, institutions responded by re-aligning their focus all the while lobbying government and coaxing industry. Etzkowitz refers to this as the 'triple helix' of university-industry-government relations and evidence of a "second academic revolution". Others have been more critical, referring to the "military-industrial-academic complex" (Giroux 2007), and "the "iron triangle" of "selfperpetuating academic, industrial and military collaboration" (Edwards 1996, 47). A further way to conceive what was happening during this period is a strengthening of the social relationship between capital and academic labour. As Marx showed, capital is a determinate logic of "self-valorising value"; it is the "automatic subject" in this case personified by strategic groups such as the NDRC and OSRD, composed of industry, government and university leaders, who sought ways to valorise academic labour by concentrating it in a handful of ma- 
jor research universities which mobilised the means of production for the production of scientific knowledge.

Although the accounts of Etzkowitz and Mowery et al are compelling, they only provide cursory mention of the struggle that has taken place over the years as the university has increased its ties with the military and industry. In particular, these accounts rarely dwell on the concern within academia and opposition to the receipt of large sums of defence funding and the ways in which academics circumvented and subverted their complicit role in this culture. A number of books have been written which do critically examine this 'second revolution' or the "iron triangle" (e.g. Edwards 1996; Leslie 1993; Heims 1993; Chomsky et al. 1997; Giroux 2007; Simpson et al. 1998; Turner 2006; Mindell 2002). As these critics have shown, there has always been a great deal of unease and at times dissent among students and staff at MIT and other universities which were recipients of large amounts of military funding. This opposition was most clearly made at MIT in the formation of the Union of Concerned Scientists (UCS 1968).

We should not generalise the MIT hackers of the 1960s and 70 s as overtly political, yet their playful disregard for conventional computing at that time can be understood as acting against the constraints of an intensifying managerialism within institutions across the US and in particular the rationalisation of institutional life pioneered by the Engineering profession and its ties with corporate America (Noble 1977). Hackers' attraction to time-sharing systems, the ability to personalise computing, programmatic access to the underlying components of computers and the use of computers for leisure activities is characteristic of an emerging sub-culture within the university and to some extent the developing counter-culture of that period (Turner 2006; Wisnioski 2012). Such accounts are vitally important to understanding the dialectical emergence of hacker culture, as are the more apolitical accounts of federal funding and the development of the entrepreneurial university.

\subsection{Venture Capital in the Garden of Eden}

Levy points to the arrival in 1959 of the TX-0 computer as a seminal moment in the history of hacking. The computer had been donated by the Lincoln Laboratory to MIT's Research Laboratory of Electronics (RLE), the original successor of the Rad Lab and today, "MIT's leading entrepreneurial interdisciplinary research organisation" (RLE 2013). Similarly, Eric Raymond (1999) points to the arrival at the RLE of the PDP-1 computer in 1961 as the moment that defined the beginning of 'hackerdom'. Notably, at that time the RLE shared the same 'Building 20' as the Tech Model Railroad Club (TMRC), the legendary home of the first hackers. The history of hacking is understandably tied to the introduction of machines like the TX0 and PDP-1 just as Richard Stallman refers to the demise of the PDP-10 as "the last nail in the coffin" for 15 years of work at MIT (Stallman 2002, 18). Given the crucial significance of these machines, a history of hacking should include a history of key technologies that excited and enabled those students and researchers to hack at MIT in the early 1960s. To some extent, Levy's book achieves this although more recent research has helped situate those technologies within the institutional, social and economic context within which Levy's biographical account implicitly resides (Ensmenger 2010; Ceruzzi 2003; Green 2010; Abbate 1999).

In 1947, the US Navy funded MIT's Servomechanisms Lab to run Project Whirlwind to develop a computer that tracked live radar data (Green 2010). The Whirlwind project was led by Jay Forrester, leading systems theorist and principle inventor of magnetic core memory, the patenting of which was marked by a dispute between MIT and the Research Corporation resulting in the cancellation of MIT's contract with the Corporation. MIT's Lincoln Lab was set up in 1951 to develop the SAGE air defence system for the US Air Force, which expanded on the earlier research of Project Whirlwind. The TMRC hackers' first computer was a TX-0 from the Lincoln Lab with its use of a cathode-ray display borrowed from the SAGE project's research into radar. Though large by today's standards, the TX-0 was smaller than Whirlwind and was one of the first transistor-run computers, designed and built at MIT's Lincoln Lab between 1956-7 (Ceruzzi 2003, 127). Much of the innovation found in the TX-0 was soon 
copied in the design of the PDP-1, developed in 1959 by the Digital Equipment Corporation (DEC).

The Digital Equipment Corporation was founded by Ken Olson and Harlan Anderson, two engineers from Lincoln Lab who had also worked on the earlier Whirlwind computer. Watching students at MIT, Olsen had noticed the appeal of the interactive, real time nature of the TX-0 compared to the more powerful but batch operated computers available and saw a commercial opportunity for the TX-0. Soon after they established their firm, they employed Ben Gurley, who had worked with them at the Lincoln Lab and designed the interactive display of the TX-0. It was Gurley who was largely responsible for the design of the PDP1. DEC is notable for many technical and organisational innovations, not least that it permitted and encouraged its clients to modify their computers, unlike its competitor, IBM, which still operated on a locked-down leasing model. DEC's approach was to encourage the use of its machines for innovation, providing "tutorial information on how to hook them up to each other and to external industrial or laboratory equipment" (ibid, 129). This not only appealed to the original TMRC hackers but appealed to many of DEC's customers too, and led to DEC becoming one of the most successful companies funded by the venture capital company, American Research and Development Corporation (ARD).

The American Research and Development Corporation, established in 1947, is regarded as the first venture capital firm and was "formed out of a coalition between two academic institutions" (Etzkowitz 2002, 90). It was founded by the 'father of venture capital', Georges Doriot, then Dean of Harvard Business School, Ralph Flanders, an Engineer and head of the Federal Reserve Bank in Boston, and Karl Compton, President of MIT. ARD employed administrators, teachers and graduate students from both MIT and Harvard. The motivation for setting up this new type of company was a belief by its founders that America's future economic growth rested on the country's ability to generate new ideas which could be developed into manufactured goods and therefore generate employment and prosperity. This built on the argument put forward by Vannevar Bush that 'basic research' should be the basis for the country's economic growth and both views were later constructed into a 'linear model' of innovation by "industrialists, consultants and business schools, seconded by economists" (Godin 2006, 640). This so-called linear process starting with basic research, which is then applied, developed and later taken into production remains a popular ideology today. However, in the late 1940s, although government was funding large amounts of R\&D in universities, the founders of ARD complained of a lack of capital, or rather a model of issuing capital, that could assist this conceived linear process of commodifying the outputs of science and so they began to incorporate one.

ARD funded DEC after Olsen and Anderson were recommended to him by Jay Forrester. This led to an investment of $\$ 100,000$ in equity and $\$ 200,000$ available in loans and within just a few years DEC was worth $\$ 400 \mathrm{~m}$ allowing ARD to take greater risks with its investments: "The huge value of the Digital Equipment stock in ARD's portfolio meant that the relatively modest profits and losses on most new ventures would have virtually no effect on the venture capital firm's worth" (Etzkowitz 2002, 98). ARD's success marked the beginning of a venture capital industry that has its origins in the post-war university and a mission to see federally funded research exploited in the 'endless frontier' of scientific progress. It led to the development of a model that many other universities copied by providing "seed" capital investment to technology firms and the establishing of 'startup' funds within universities.

One of the catalysts for Stallman leaving MIT was that many of the hackers working with him left to join two companies spun off from the Al Lab to meet a growing demand for Lisp Machines from the Al research community. Four colleagues left to join Lisp Machines, Inc. (LMI), led by Stallman's mentor, the 'hacker's hacker', Richard Greenblatt, while fourteen hackers left to join Symbolics, Inc. a company led by Russell Noftsker, who was Head of the Al Lab for eight years and had hired Stallman. For a while in 1979, Noftsker and Greenblatt discussed setting up a company together that sold Lisp Machines, but they disagreed on how to initially fund the business. Greenblatt wanted to rely on reinvesting early customer orders and retain full control over the company while Noftsker was keen to use a larger amount of venture capital, accepting that some control of the company would be given up to the inves- 
tors, one of which was ARD. ${ }^{1}$ Greenblatt and Noftsker couldn't agree and so set up companies independent of each other, attracting most of Stallman's colleagues.

Within a year of the two Al Lab spin-offs doing business, Stallman and Symbolics clashed over the sharing of code (he refers to this as the "software wars"). Having been deserted by his fellow hackers, Stallman had made efforts to ensure that everyone continued to benefit from Symbolics enhancements to the Lisp Machine code, regularly merging Symbolics code with MIT's version which Greenblatt's company used. Like other MIT customers, Symbolics licensed the Lisp Machine code from MIT and began to insist that their changes to the source code could not be redistributed beyond MIT, thereby cutting off Greenblatt's Lisp Machines, Inc. and other MIT customers. Stallman's efforts to keep the old AI Lab hacker community together through the sharing of distributed code came to an end. Lisp Machines went bankrupt in 1985 while Symbolics remained active until the end of the Cold War. With the military's appetite for Al technologies on the decline and venture-funded commodity computing on the rise, Symbolics represented an earlier period of computer science as it attempted to escape the academy.

\section{The Systematic Conversion of Intellectual Activity into Intellectual Capital}

The institutionalised commercialisation of research at MIT began in the 1930s, when MIT had developed a consultancy policy and one of the first university patent policies, clearly indicating that the Institute had a claim to the profits deriving from its research activity. By 1963, MIT had cancelled its Agreement with the Research Corporation and fully internalised the process of identifying and managing patents. In this respect, MIT was at the forefront of a movement among US universities to undertake "the systematic conversion of intellectual activity into intellectual capital and, hence, intellectual property" (Noble 1998) - to engage in 'entrepreneurial science' where research groups are run as de facto firms (Etzkowitz 2003). The military-funded work in Artificial Intelligence during the 1970s, which early hackers contributed to, should be understood within the context of the academy's role in the Cold War (Leslie 1994; Chomsky et al. 1997; Simpson 1998, Lowen 1997). This systematic programme of funded research across a number of disciplines consequently increased the number of commercial opportunities ('technology transfers' in the jargon of linear model innovation), not least in the fields of electronics, engineering and the emerging discipline of computer science.

The development of land grant universities and the practice of applied science, patronised by large sums of government funding, provided the conditions for a hacker culture to emerge in the early 1960s, which remained tied to structural changes taking place within US higher education and its shift towards entrepreneurialism in the 1970s. Stallman has said that he and his colleagues did not object to the commercialisation of their work, but the instruments of this advancing entrepreneurialism (patents, copyright, licenses) were at odds with at least one of the long held "institutional imperatives" of scientific practice: "Communism" (Merton 1973).

In a sincere but retrospectively naive way, Frederick Cottrell recognised this in 1912, when he established the Research Corporation as a charity and donated his patents so as to benefit public social welfare and provide philanthropic grants for further scientific work. However, twenty years later, in the midst of the Depression, MIT asserted institutional interest in the 'intellectual property' of its researchers and sought a majority cut of the income deriving from its patents. It took a further three decades or so for MIT to relinquish the use of the Research Corporation altogether and fully internalise the commercial exploitation of scientific research. Writing in 1973, Merton's "communism" as a foundation of the scientific ethos seems both an ironic use of the term given that most scientific research in the US was being funded through the Cold War agencies, and removed from the reality of what was happening within institutions as they advanced 'entrepreneurial science'. Merton understood this, and

\footnotetext{
${ }^{1}$ See Noftsker's autobiographical account on Wikipedia http://en.wikipedia.org/wiki/User:Russell Noftsker Retrieved $2^{\text {nd }}$ April 2013. This account is especially useful in understanding the formation of the Al Lab, the funding arrangements at the time, and the fluid movement of Engineers between the academy and industry.
} 
his description of the "communal character of science" (Merton 1973, 274) surely refers more to an ideal of a pure, vocational science than actual professional practice (Pielke 2012; Shapin 2008).

The 'MIT model' was later universalised within the US as the Bayh-Dole Act (1980) and provided universities with the legal means and obligation to exploit federally funded research. In doing so, the Act formalised not just a mechanism for patenting but an academic environment that was overall more entrepreneurial. As Etzkowitz states: "In addition to rationalising and legitimising university patenting and licensing, the law induced a psychological change in attitudes towards technology transfer as well as an organisational change in encouraging the creation of offices for this purpose" (2002 114).

\section{Conclusion}

I have argued that the material conditions for the emergence of hacking are to be found in a series of historical attempts to valorise academic labour (i.e. 'research') that were both extrinsic and intrinsic to the academy.

The provision of land grants at the appeal of agriculturalists marked an early stage in the process of valorisation in higher education, when the creative power of academic labour was subsumed by the treadmill logic of capital. It marked a process by which the unproductive labour of an emerging profession of academic scientists was co-ordinated by the State, industry and leading academics, for productive use.

This formal process of subordination to capital went through further stages over subsequent decades as the valorisation process moved from being extrinsic to the academic labour process to being institutionally internalised during the 1970s at MIT and a few other research intensive universities and then generalised by the Bayh-Dole Act in 1980. This was not simply a 'capture' or 'enclosure' of academic work but through the development of a new discourse of post-war science by leading academics bolstered by the awesome power of the atomic bomb, a reconceptualization took place of the production, distribution and consumption processes of scientific research, its justification and its objectives, its means and its ends. Through the joint efforts of academics and politicians, the purpose and practice of scientific research was positioned as a 'basic' vehicle for the accumulation of capital left to the 'invisible hand' of the market, with the use and subsequent growth of computing at its core (Pielke 2012; Godin 2009, 2006; Polanyi 1967; Shapin 2008).

What this history reveals is that the subordination of hackers' labour to the imperative of valorisation involved a number of actors inside and outside the university, in the public sector and private industry. Taking this view, both the 'triple helix' and the 'iron triangle' of academic, industrial and State relations, are merely ways of articulating the 'capital relation' (i.e. the relationship between capital and labour), which works against our conceptions of public and private. Therefore the resistance and overcoming of this imperative cannot be measured by the extent that the production of science and technology is conducted openly or held in public through legalistic means. This critique of hacking points to the urgent need for science and therefore the university itself to be re-produced apart from the imperatives of the reproduction of capital and its source of value, labour. It suggests that the production of scientific knowledge should be mediated less by the current dialectic of open vs. closed in higher education and elsewhere ('open science', 'open data', 'open source', etc.), but by its effective contribution to a post-capitalist transformation in what constitutes labour and our capacity to reproduce ourselves.

This preliminary analysis also suggests that even if characterised by more open access to the distribution of scientific knowledge, the trajectory of 'progress' in society will remain mediated by the requirements of capital i.e. the concurrent necessity and discarding of human labour as the source of value. Hacking as a form of labour no doubt contributes to capital's measure of what currently constitutes 'progress' but through the legal mechanism of copyleft, free software hackers insist upon "reciprocity in perpetuity" the perpetuation and socialisation of access to software code and other means of production (e.g. 'open hardware') (Pederson $2010,265)$. However, a critique of hacking which aims to reveal the contradiction between 
the hack as object and hacker as subject runs the risk of fetishising hacker culture and positing them as a 'sub' or 'counter' culture, somehow set apart from the totality of the social relations of capital and other forms of working class struggle.

The critique proposed here seeks to position hackers not simply as the subjects of history but as an objectification of the social relations constituted by capital in the university as a historically specific form of labour. As both the dialectical subject and object of critique, hacking is then neither explained away as a functional outcome of 'academic capitalism' nor fetishized as a revolutionary subject whose novelty will liberate the means of production. Instead, hacking conceived as a form of labour produced by a series of historical moments in the valorisation of US higher education institutions and a concurrent re-conception of the idea, purpose and method of science, is regarded as a transitional constitution of the social relations of capital to be abolished through the socialisation of its critical achievements. Such achievements are by no means guaranteed and until such time, the "commons-based", "peer-to-peer", "open" techniques of production and distribution, including the legal means of protecting those techniques, can be understood as contemporary forms of struggle by labour that acts in, against and beyond the university and other institutionalised expressions of the social relations of capital.

By focusing on hacking as a historically constituted form of labour, we shift the focus of its critique, and therefore our critique of hacker culture, away from matters of exchange and the market such as the free circulation of software and the ethics of private property for reproducible goods, towards the peculiar and novel characteristics of hacking as labour, struggling to overcome the necessity of itself as a form of self-reproduction.

\section{References}

Abbate, Janet. 1999. Inventing the Internet. MIT Press.

Adams, Gordon and Nancy Sokoloff. 1982. The Politics of Defense Funding: The Iron Triangle. Transaction Publishers.

Atkinson, Richard C. and William A. Blanpied. 2007. Research Universities: Core of the U.S. Science and Technology System. Accessed July 31, 2013.

http://cshe.berkeley.edu/publications/publications.php?id=256

Bayh-Dole Act. 1980. Accessed July 31, 2013. http://www.law.cornell.edu/uscode/text/35/partII/chapter-18

Bush, Vannevar. 1945. Science The Endless Frontier. Accessed July 31, 2013. https://www.nsf.gov/od//pa/nsf50/vbush1945.htm

Cabinet Office. 2013. Open Data Charter. Accessed July 31, 2013. https://www.gov.uk/government/publications/open-data-charter

Canizares, Claude R. 2007. Sixty-Six Years of Sponsored Research. MIT Faculty Newsletter 19 (3). Accessed July 31, 2013. http://web.mit.edu/fnl/volume/193/canizares.html

Ceruzzi, Paul E. 2003. A History of Modern Computing. MIT Press.

Chomsky, Noam, Howard Zinn and Immanuel M. Wallerstein. 1998. The Cold War \& the University: Toward an Intellectual History of the Postwar Years. New Press.

Clarke, Simon. 1980. The Value of Value. Capital and Class 4 (1): 1-17.

Coleman, E. Gabriella. 2012. Coding Freedom. The Ethics and Aesthetics of Hacking. Princeton University Press.

DiBona, Chris, Sam Ockman and Mark Stone. 1999. Open Sources: Voices of the Open Source RevoIution. O'Reilly Media, Inc.

Edwards, Paul. 1996. The Closed World: Computers and the Politics of Discourse in Cold War America. MIT Press.

Ensmenger, Nathan. 2010. The Computer Boys Take Over. Computers, Programmers and the Politics of Technical Expertise. MIT Press.

Etzkowitz, Henry. 1997. Universities and the Global Knowledge Economy: A Triple Helix of UniversityIndustry-Government Relations. Continuum.

Etzkowitz, Henry. 2001. The Second Academic Revolution and the Rise of Entrepreneurial Science. Technology and Society Magazine, IEEE, 20 (2): 18-20.

Etzkowitz, Henry. 2002. MIT and the Rise of Entrepreneurial Science. Routledge. 
Foreign and Commonwealth Office. 2013. G8 Science Ministers Statement. Accessed July 31, 2013. https://www.gov.uk/government/news/g8-science-ministers-statement

Forman. 1987. Behind Quantum Electronics: National Security as Basis for Physical Research in the United States, 1940-1960, Historical Studies in the Physical and Biological Sciences 18 (1): 149229.

Gillmore, C. Stewart .2004. Fred Terman at Stanford. University of Stanford Press.

Giroux, Henry A. 2007. The University in Chains: Confronting the Military- ndustrial-Academic Complex. Paradigm Pub.

Godin, Benoit. 2006. The Linear Model of Innovation: The Historical Construction of an Analytical Framework. Science, Technology and Human Values 31 (6): 639-667.

Godin, Benoit. 2009. The Making of Science, Technology and Innovation Policy: Conceptual Frameworks as Narratives, 1945-2005. Centre Urbanisation Culture Societe, Montreal. Accessed July 31, 2013. http://www.csiic.ca

Green, Tom. 2010. Bright Boys. A K Peters Ltd.

Hafner, Katie and Matthew Lyon. 2003. Where Wizards Stay Up Late: The Origins of the Internet. Pocket Books.

Himanen, Pekka. 2001. The Hacker Ethic and the Spirit of the Information Age. Vintage.

Holloway, John, Fernando Matamoros and Sergio Tischler ,eds. 2009. Negativity and Revolution. Adorno and Political Activism. Pluto Press.

Heims, Steve Joshua. 1993. Constructing a Social Science for Postwar America: The Cybernetics Group, 1946-1953. MIT Press.

Heinrich, Michael. 2012. An Introduction to the Three Volumes of Karl Marx's Capital. Monthly Review Press.

Johns, Adrian. 2009. Piracy. The Intellectual Property Wards from Gutenberg to Gates. The University of Chicago Press.

Jordan, Tim. 2008. Hacking: Digital Media and Technological Determinism. Polity Press.

Kaiser, David, ed. 2010. Becoming MIT: Moments of Decision. MIT Press.

Kelty, Christopher M. 2008. Two Bits. The Cultural Significance of Free Software. Duke University Press.

Leslie, Stuart W. 1993. The Cold War and American Science: The Military-Industrial-Academic Complex at MIT and Stanford. Columbia University Press.

Lessig, Lawrence. 2004. Free Culture. How Big Media Uses Technology and the Law to Lock Down Culture and Control Creativity. The Penguin Press.

Levy, Steven.1984. Hackers: Heroes of the Computer Revolution. Penguin Books.

Lowen, Rebecca S. 1997. Creating the Cold War University. The Transformation of Stanford. University of California Press.

Lucas, Christopher J. 1994. American Higher Education. A History. St. Martin's Griffin.

Markoff, John. 2005. What the Dormouse Said: How the Sixties Counterculture Shaped the Personal Computer Industry. Penguin Books.

Marx. 1976. Capital Volume I. Penguin Classics.

Marx. 1978. The Value Form. Accessed October 18, 2013. http://www.marxists.org/archive/marx/works/1867-c1/appendix.htm

Marx. 1874. Conspectus of Bakunin's Statism and Anarchy. Accessed July 31, 2013. http://www.marxists.org/archive/marx/works/1874/04/bakunin-notes.htm

Merton, Robert K. 1973. The Sociology of Science. The University of Chicago Press.

Mindell, David A. 2002. Between Human and Machine: Feedback, Control, and Computing Before Cybernetics. JHU Press.

Morrill Act. 1862. Accessed July 31, 2013. http://www.law.cornell.edu/uscode/text/7/304

Mowery et al. 2004. Ivory Tower and Industrial Innovation. University-Industry Technology Transfer Before and After the Bayh-Dole Act. Stanford University Press.

Neary, Mike. 1999. Labour: The Poetry of the Future. In Global Humanisation: Studies in the Manufacture of Labour, edited by M. Neary, 164-193. Mansell.

Noble, David F. 1977. America by Design: Science, Technology, and the Rise of Corporate Capitalism. Oxford University Press.

Noble, David F. 1998. Digital Diploma Mills: The Automation of Higher Education. First Monday (3) 1-5 January 1998. Accessed July 31, 2013. http://firstmonday.org/ojs/index.php/fm/article/view/569/490

Pederson, J. Martin. 2010. Property, Commoning and the Politics of Free Software. The Commoner 14, Winter 2010. Accessed July 31, 2013. http://www.commoner.org.uk/index.php?p=107 
Pielke Jnr., Roger. 2012. Basic Research as a Political Symbol, Minerva 50 (3): 339-361.

Polanyi, Michael. 1962. The Republic of Science: Its Political and Economic Theory. Minerva 1: 54-74.

Postone, Moishe. 1993. Time, Labour and Social Domination. Cambridge University Press.

Postone, Moishe. 2004. Critique and Historical Transformation. Historical Materialism 12 (3): 53-72.

Raymond, Eric S. 1999. A Brief History of Hackerdom. In Open Sources: Voices of the Open Source Revolution, edited by DiBona et al., 19-29. O'Reilly Media, Inc.

Research Laboratory of Electronics (RLE). 2013. Accessed July 31, 2013. http://www.rle.mit.edu/about/

The Royal Society. 2012. Science as an Open Enterprise. Accessed July 31, 2013. http://royalsociety.org/policy/projects/science-public-enterprise/report/

Shapin, Steven. 2008. The Scientific Life. A Moral History of a Late Modern Vocation. The University of Chicago Press.

Simpson, Christopher. 1998. Universities and Empire: Money and Politics in the Social Sciences During the Cold War. The New Press.

Slaughter, Sheila and Larry Leslie. 1997. Academic Capitalism: Politics, Policies, and the Entrepreneurial University. John Hopkins University Press.

Soderberg, Johan. 2008. Hacking Capitalism. Routledge.

Sohn-Rethel, Alfred. 1978. Intellectual and Manual Labour. A Critique of Epistemology. Humanities Press.

Stallman, Richard. 1981. EMACS Manual for ITS Users. AI Memo 554. MIT AI Lab. $22^{\text {nd }}$ October 1981. Accessed July 31, 2013. ftp://publications.ai.mit.edu/ai-publications/pdf/AIM-554.pdf

Stallman, Richard. 1988. What is Copyleft? GNU's Bulleting 1 (5). Accessed July 31, 2013. https://www.gnu.org/bulletins/bull5.html - SEC5

Stallman, Richard. 2002. Free Software Free Society: Selected Essays of Richard M. Stallman. GNU Press.

Sterling, Bruce. 1992. The Hacker Crackdown. Bantam Books.

Stratton, Julius Adams and Loretta H. Mannix. 2005. Mind And Hand: The Birth Of MIT. MIT Press.

Tai, Andy. 2001. The History of the GNU General Public License. Accessed July 31, 2013. http://www.free-soft.org/gpl history/

Turner, Fred. 2006. From Counterculture to Cyberculture: Stewart Brand, the Whole Earth Network, and the Rise of Digital Utopianism. University of Chicago Press.

Union of Concerned Scientists. 1968. Founding Document: 1968 MIT Faculty Statement. Accessed July 31, 2013. http://www.ucsusa.org/about/founding-document-1968.html

Williams, Sam and Richard Stallman. 2010. Free as in Freedom. Richard Stallman's Crusade for Free Software. SoHo Books.

Wisnioski, Matthew. 2012. Engineers for Change: Competing Visions of Technology in 1960s America. MIT Press.

\section{About the Author}

Joss Winn

is a Senior Lecturer in the Centre for Educational Research and Development, University of Lincoln. 